\title{
SEJARAH POLITIK POLITISASI AGAMA DAN DAMPAKNYA DI INDONESIA
}

\author{
Sumanto Al Qurtuby \\ Pendiri dan Direktur Nusantara Institute; \\ Dosen Antropologi Budaya di King Fahd University of Petroleum \\ and Minerals, Dhahran, Arab Saudi
}

\section{Abstrak}

Sejak beberapa tahun terakhir ini, setelah sekian lama mati suri, politisasi agama, khususnya politisasi Islam, kembali menyeruak ke ruang-ruang publik Indonesia.Rontoknya rezim Orde Baru menyebabkan bangkitnya kembali para petualang agama yang dulu sempat "dimumikan" oleh Suharto karena dianggap membahayakan stabilitas dirinya, cendana, dan kroninya. Ketika Suharto tak lagi berkuasa, mereka pun ber-euforia dan berpesta pora. Tak pelak, politisasi agama (Islam) yang cenderung berlebihan dan overdosis ini telah menimbulkan dampak buruk bagi kehidupan berbangsa, beragama, dan bernegara di Tanah Air. Tulisan ini bermaksud mengulas sejarah politik politisasi agama dan dampaknya di masyarakat serta prospek Indonesia di kemudian hari di tengah serbuan politik identitas yang kian menggema.

Kata Kunci : Politisasi agama, politik identitas, Islam, Islamisme, Islamis, toleransi, intoleransi, pluralisme, Indonesia

\section{Pendahuluan}

Sebelum dijelaskan tentang sisi negatif, dampak buruk, risiko, atau bahaya overdosis politisasi agama bagi masyarakat, mungkin ada baiknya kalau saya jelaskan terlebih dahulu tentang makna "politisasi agama" itu sendiri, khususnya politisasi Islam.

Definisi umum "politisasi agama" (politicization of religion) adalah penggunaan norma, doktrin, ajaran, prinsip, teks, diskursus, dan simbol-simbol keagamaan untuk tujuan politik praktis-kekuasaan. Dengan kata lain, agama digunakan, dimanipulasi, dan dieksploitasi sedemikian rupa, baikoleh individu maupun kelompok sosial (social group) tertentu,untuk kepentingan politik praktis dan kekuasaan tertentu, dan tentu saja demi keuntungan material ekonomi tertentu. 
Dalam konteks ini maka istilah "politisasi agama” kurang lebih sama dengan "agama yang dipolitisir" (politicized religion).Secara konseptual, istilah "politicized religion" berbeda dengan "political religion" (agama politik) maupun "religious politics" (politik agamis). Istilah "agama politik" mengandaikan tentang adanya atau eksistensi dimensi politik yang sangat lumrah dalam agama (teks maupun ajaran keagamaan). Sementara istilah "politik agamis" mengandung makna tentang adanya "kesalehan politik", yakni berpolitik dengan menampilkan ideom-ideom atau simbol-simbol keagamaan tertentu sehingga tampak saleh di permukaan (meskipun isinya belum tentu saleh). Inilah yang kadang disebut "agamaisasi politik", yakni memberikan baju "sakral-relijius" terhadap politik yang profan-sekuler.

Dalam perkembangannya, "politisasi agama" memiliki kesan negatif atau makna peyoratif. Padahal sebetulnya "politisasi agama” itu sesuatu yang sangat wajar karena sejak detik pertama agama "lahir" atau muncul di muka bumiini, ia sudah sangat politis atau berdimensi politik. Ada agama yang lahir sebagai “pemberontakan teologis” atau "protes kultural” atas kepongahan, keangkuhan, dan keserakahan kekuasaan yang didominasi atau dikontrol oleh elit politik dari kelompok tertentu.

Tetapi ada pula agama yang lahir dan diciptakan oleh para "pemangku ritual" (ritual elders) guna mengstabilkan situasi sosial dan mengontrol komunitas dan masyarakat sekaligus memelihara kepentingan-kepentingan politik-ekonomi tertentu. Berbagai kajian antropologi agama terhadap kemunculan agamaagama suku di berbagai belahan dunia menunjukkan fenomena ini (lihat misalnya Stein dan Stein 2017; Stiles 1993). Agama juga bisa jadi hadir karena adanya kebutuhan spiritual-metafisikal-eskatalogikal umat manusia tertentu. Saya katakan "tertentu” karena tidak semua umat manusia membutuhkan hal ini.

Islam, dalam batas tertentu, bisa masuk kategori sebagai "agama pemberontak". Ia hadir sebagai bentuk dari "perlawanan teologis-kultural" atas arogansi, dominasi, dan kontrol kekuasaan politik-ekonomi sekelomok elit suku di Makah (dan juga Madinah). Banyak sekali teks dasar keislaman (dalam Al-Qur'an dan Hadis) yang mengkritisi bentuk-bentuk kekuasaan sektarian yang tiran, arogan, menindas, monopolistik, dan anti terhadap nilai-nilai kemanusiaan universal serta kritik terhadap sistem politik-ekonomi di tempat asal-muasal Islam lahir (lihat misalnya Esack 1996; Engineer 1990; Al Qurtuby 2013). Dalam sejarah 
perkembangannya, Islam juga sangat politis dan semakin terorganisir watak kepolitikan Islam sejak pendirian dinasti-dinasti keislaman (lihat Sonn 2015).

Dalam konteks ini,maka politisasi agama menjadi terkesan negatif dan buruk lantaran ada pengandaian atau asumsi yang keliru, yakni kalau agama itu hanya mengurusi masalah ritus atau ritual atau moralitas umat, minimal para pemeluknya. Meskipun itu tidak salah. Tapi bukan berarti bahwa agama hanya melulu berurusan dengan hal-ikhwal yang berkaitan dengan moral, spiritual, dan ritual. Selain dimensi ritual, spiritual, dan moral ini, agama juga berdimensi politik dan bahkan ideologi.

Charles Glock dan Rodney Stark dalam Religion and Tension in Society mengatakan bahwa agama itu sangat multidimensi yang setidaknya memiliki lima dimensi utama, yaitu experiential (feeling), ritualistic (practice), ideological (belief), intellectual, dan consequential (ethical). Saya ingin menambahi bahwa agama juga berdimensi moral, spiritual, supranatural, eskatologis, dan politis, dan itu sangat jelas dalam bentangan sejarah peradaban manusia. Kata "politik" tentu saja tidak melulu dimaknai sebagai "kekuasaan agung" atau aktivitas sebuah negara tetapi sebagai sebuah cara atau aktivitas yang dilakukan oleh seseorang guna meningkatkan status atau otoritas dalam sebuah kelompok tertentu.

Jadi, jelasnya, politisasi agama itu sebetulnya sesuatu yang sangat lumrah dan memang sudah dilakukan oleh banyak komunitas agama sejak zaman dahulu kala. Ia tidak melulu berdampak buruk dan negatif. Kadang kala, politisasi agama juga berdampak baik dan positif. Baik-buruk atau negatif-positif adalah sesuatu yang sangat subyektif dan relatif. Baik dan positif bagi orang dan kelompok tertentu, belum tentu baik dan positif bagi orang dan kelompok lain. Begitu pula, buruk dan negatif bagi orang dan kelompok tertentu, juga belum tentu buruk dan negatif bagi orang dan kelompok lain.

Politisasi agama menjadi tidak wajar dan acap kali berdampak buruk bagi kemanusiaan dan negatif bagi relasi antarindividu maupun antarkelopok sosial kalau dilakukan secara berlebihan. Dengan kata lain, politisasi agama yang overdosis, kemaruk, brutal, dan tanpa mengindahkan etika sosial dan rasa kemanusiaan inilah, seperti saya jelaskan di belakang nanti, yang menyebabkan sejumlah keburukan dan kenegatifan di masyarakat, bangsa, dan negara. Overdosis politisasi agama inilah yang harus diminimalisir dan bahkan dicegah agar tidak membawa malapetaka berkepanjangan. 
Begitu pula, "agamaisasi politik" (proses pengalungan jubah agama dalam politik praktis) sebetulnya juga wajar kalau dilakukan dalam batas tertentu. Dan tidak selamanya, "agamaisasi politik" berdampak buruk dan negatif. Ia menjadi tidak wajar dan sering kali berdampak buruk-negatif kalau dilakukan secara berlebihan dan tanpa mengindahkan norma-norma atau nilai-nilai kemanusiaan universal (Patrikios 2007; (Ivanescu 2013: 309-325).

\section{Dinamika Hubungan Agama dan Politik}

Dalam bentangan sejarah peradaban manusia, relasi agama dan politik sangat erat dan berkelindan, dan selalu menarik diperbincangkan. Sarjana sosial, ilmuwan politik, akademisi, agamawan, politisi, aktivis, bahkan birokrat samasama bergairah membicarakan masalah agama dan politik dari berbagai sudut pandang, teori, dan metode riset dan analisis.

Ada cukup banyak karya akademik yang mendiskusikan fenomena hubungan agama dan politik ini, baik yang kontemporer maupun yang klasik. Untuk yang kontemporer khususnya, Jonathan Fox, misalnya, seorang profesor ilmu politik di Bar-Ilan University, Israel, telah menulis banyak karya akademik mengenai hubungan komplek dan njlimet antara agama (berbagai agama di dunia) dan politik (berbagai sistem dan aktivitas politik). Salah satu karya Jonathan Fox yang cukup komprehensif tentang hal ini adalah An Introduction to Religion and Politics: Theory and Practice (2012), sebuah "tour de force" yang mengombinasikan antara teori-teori relasi agama dan politik serta data survei mengenai kebijakankebijakan politik mengenai keagamaan dari sekitar 177 pemerintah atau negara.

Hasil survei ini menunjukkan adanya pluralitas sikap terhadap agama dan politik. Pemerintah yang mendukung maupun membatasi ruang gerak agama sama-sama besarnya. Satu sisi, banyak pemerintah yang "mengunci" peran sentral agama di publik, sementara di pihak lain banyak juga agama yang mempengaruhi dan mendikte dunia politik. Netralitas politik terhadap agama semakin menjadi barang langka. Pada saat yang sama, agama juga menjadi entitas yang semakin penting dalam politik. Fox menulis: "Religion is becoming an inescapable issue in politics".

Fox benar. Ada negara-negara yang memisahkan secara ketat antara politik dan agama seperti sejumlah negara di Eropa. Tapi ada pula yang menganggap agama sebagai instrumen penting dalam politik-pemerintahan seperti Amerika Serikat dan berbagai negara yang mayoritas berpenduduk Muslim, termasuk Indonesia. 
Tetapi, perlu dicatat, itu bukan berarti bahwa masyarakat di sebuah negara mengikuti pola pemikiran dan pandangan yang sama dan seragam. Pluralitas pemikiran, pandangan, dan praktek masyarakat selalu ada dan hadir dimanamana.

Dengan kata lain, meskipun di sejumlah negara Eropa modern, banyak masyarakat yang menginginkan pemisahan agama dari politik, tetapi banyak juga yang menginginkan kembalinya agama dalam dunia politik-pemerintahan seperti yang terjadi di zaman Eropa abad pertengahan. Munculnya gagasan demokrasi Kristen di Eropa seperti pernah ditulis oleh Stathis Kalyvas, The Rise of Christian Democracy in Europe, menunjukkan adanya munculnya kembali keinginan sejumlah kelompok Kristen kontemporer di Eropa tentang pentingnya mengawinkan kekristenan (keagamaan) dengan dunia politik praktis pemerintahan.

Hal yang sama juga terjadi di Amerika. Meskipun banyak pihak yang menganggap pentingnya norma-norma Judeo-Christianity dalam mengarahkan jalannya pemerintahan, tetapi banyak juga yang berpendirian agama sebagai penghambat jalannya demokrasi liberal sehingga harus diprivatkan jangan sampai menjadi agama publik yang bisa berpotensi mengacaukan sistem dan tatanan demokrasi liberal yang bertumpu pada kekebasan individu dan sekularisme.

Sejarah Indonesia-dari dulu hingga kini, sebelum maupun sesudah kemerdekaan-juga tidak lepas dari kontroversi relasi agama (khususnya Islam) dan politik. Ada kelompok yang menganggap Islam dan politik adalah dua entitas yang tidak bisa dipisahkan. Ada juga yang berargumen Islam dan politik harus dipisah secara ekstrim. Yang lain lagi menolak agama terlibat dalam politik praktis-kekuasaan tetapi membolehkan politik non-praktis, yaitu sejenis politik kerakyatan diluar negara atau pemerintah.

Dulu, pada masa penjajahan Belanda, banyak para ulama yang bekerja sama dengan kompeni, baik sebagai penasehat politik-agama seperti Habib Usman bin Yahya (1822-1913) yang menjadi penasehat Belanda atas usul Christian Snouck Hurgronje, sebagai pejabat pengadilan agama, maupun sebagai petugas keagamaan untuk mengurusi masjid dan ritual keislaman. Tetapi ada juga para ulama dan tokoh Muslim yang menolak kongkalikong dengan Belanda dan memilih menjadi oposan pemerintah kolonial yang menginisiasi perlawanan di sejumlah daerah di seluruh Hindia Belanda. 
Setelah Indonesia merdeka, para elit Muslim terbelah: sebagian ada yang pro perkawinan antara Islam dan politik, sebagian lagi memilih perceraian Islam dan politik. Era Orde Lama menunjukkan, kelompok Islam politik gagal meraih panggung kekuasaan setelah Masyumi dibekukan oleh Bung Karno di awal 1960an.

Fenomena ini berlanjut di zaman Orde Baru. Pak Harto yang terkenal diktator bertangan dingin juga tidak memberi ruang secuilpun bagi pertumbuhan kelompok Islam politik. Sejumlah faksi Islam politik dibonsai di PPP (Partai Persatuan Pembangunan). Sementara kelompok Islamis radikal diganyang (seperti Komando Jihad). Kelompok separatis Muslim juga diserbu (seperti Gerakan Aceh Merdeka).

Waktu itu, Pak Harto hanya memberi ruang bagi perkembangan Islam budaya karena itu para aktivis Islam politik (termasuk para pentolan eks-Masyumi) memilih bungkam dan tiarap. Mereka melakukan berbagai aktivitas pengajian dan pertemuan keagamaan secara diam-diam, tidak berani secara terbuka. Karena mereka tahu, Pak Harto tidak menyukai kelompok Muslim yang menggunaan Islam sebagai instrumen politik untuk meraih kekuasaan yang bisa mengganggu stabilitas nasional,Orde Baru, Cendana, dan Pak Harto sendiri.

Hanya pada awal 1990-an saja, Pak Harto mulai melirik sejumlah teknokrat Muslim modernis dan cendekiawan Islam moderat yang ternyata sebagian justru menjadi "Brutus" bagi Pak Harto yang turut menikamnya dari belakang ketika Indonesia diterpa gelombang krisis ekonomi dan moneter yang membawa pada tumbangnya kekuasaan Pak Harto dan Orde Baru.

Lengsernya Pak Harto dan rontoknya rezim Orde Baru membawa "berkah" dan angin segar bagi kelompok Islam politik dan kaum Islamis yang sejak dulu menginginkan Islam terlibat secara total dalam kepolitikan guna mengatur jalannya roda pemerintahan dan kenegaraan serta berambisi ingin menjadikan Indonesia menjadi negara berbasis Islam secara formal.

Mereka yang dulunya "ngumpet" mulai bermunculan dan menggelar berbagai acara dan aktivitas yang berkaitan dengan Islam politik secara terbuka dan terang-terangan. Lengsernya Pak Harto, dengan demikian,membuka jalan bagi lahirnya iklim demokrasi yang memberi ruang lebar-lebar bagi kebebasan individu (termasuk kaum Islamis tadi) untuk berkespresi.

Tetapi ironisnya, atas nama agama, sejumlah kaum Islamis dan kelompok Islam radikal dan intoleran justru sering berbuat ulah memadamkan api kebebasan 
dengan memberangus berbagai kelompok atau sekte keagamaan yang mereka hakimi sendiri sebagai sesat dan menyimpang dari "kanon resmi" Islam. Mereka mau hidup bebas-merdeka tetapi tidak mau memberi ruang kebebasankemerdekaan itu kepada orang dan kelompok lain. Ironisnya lagi, mereka juga mengecam demokrasi sebagai "budaya kafir", Pancasila sebagai "sistem thoghut", Indonesia sebagai negara tidak Islami, dan seterusnya. Padahal, mereka bisa mengekspresikan pendapat dengan bebas dan merdeka itu justru karena demokrasi.Dalam sistem politik otoriter, seperti zaman Orde Baru dulu, kebebasan menjadi barang mewah.

Pelan tapi pasti, berbagai kelompok Islam politik ini semakin liar dan menjadijadi karena mendapatkan panggung lebar untuk berekspresi dalam payung demokrasi. Akibatnya, banyak hal mulai tampak overdosis: semua diukur dari kacamata Islam dan harus sesuai dengan norma-norma Islam. Padahal, apa yang mereka klaim sebagai ajaran Islam itu dalam realitasnya sebetulnya adalah wacana keislaman yang diproduksi oleh sejumlah pemikir-aktivis Muslim dan ulama favorit mereka. Seperti konsep "Negara Islam” yang mereka usung dan klaim sebagai "ajaran Islam” itu jelas merupakan produk politik sekuler kontemporer pascakolonialisme yang diinisiasi oleh tokoh-tokoh seperti Abul A'la al-Maududi atau Sayyid Qutb, yang tidak ada kaitannya sama sekali dengan ajaran Islam.

\section{Politisasi Agama dalam Sejarah Sosial Indonesia}

Seperti dijelaskan di atas, relasi agama dan politik sudah terjadi cukup lama dalam sejarah sosial Indonesia. Demikian pula sejarah politisasi agama di Indonesia khususnya juga sudah menjadi fenomena dan fakta yang tidak modern lagi. Jauh sebelum Indonesia merdeka tahun 1945, politisasi agama, khususnya politisasi Islam, sudah menjadi pemandangan lumrah di masyarakat.

Dulu, sejak awal abad ke-20 ketika berbagai kelompok sosial-politik-keagamaan mulai bermunculan di "Indonesia”, berbagai kelompok Islam, baik yang puritanreformis (seperti Persis, Muhammadiyah, dan lainnya), tradisionalis (seperti Nahdlatul Ulama, Perti, Alkhairat, dan lainnya), maupun yang komunis-sosialis (seperti Sarikat Dagang Islam, Partai Komunis Indonesia, dan lainnya) samasama menggunakan teks, wacana, idiom, jargon, dan simbol keislaman tertentu untuk menarik simpati publik masyarakat pada ormas yang mereka prakarsai. 
Jangankan ormas seperti NU, Muhammadiyah, atau Persis yang jelas-jelas banyak kaum agamawan, PKI pun sama. Misalnya, salah satu tokoh sentral PKI kala itu yang juga seorang Muslim aktivis bernama Haji Misbach (1976-1926) atau dikenal "Haji Merah" getol sekali berdakwah dan berkampanye tentang persamaan antara Islam dan Marxisme-Komunisme. Haji Misbach adalah salah satu tokoh Muslim yang getol menggunakan Islam sebagai instrument politik untuk melawan kolonialisme Belanda yang dianggap sebagai representasi kaum Borjuis dan penindas.

Bahkan jauh sebelum abad ke-20 pun, ketika ormas-ormas keislaman belum terbentuk, politisasi agama (Islam) sudah eksis berjalan dan marak di "Indonesia" dari Aceh sampai Maluku. Perseteruan antara pengikut fanatik fikih dan tasawuf (Sufisme), antara kaum tua penjaga adat versus kaum muda yang properubahan, antara kaum putihan di kauman dan kaum abangan di pedalaman, antara ulama yang kontrakolonial dengan mereka yang prokolonial, antara klerik yang membela kemapanan kerajaan dengan mereka yang antikerajaan, dlsb, semua memakai dalil, dasar, dan argumen dari teks, doktrin, ajaran, wacana, tafsir, norma, jargon, dan simbol keagamaan (keislsman).

Munculnya ormas-ormas keislaman di awal abad ke-20 sejatinya hanya untuk "mewadahi" perpecahan, faksionalisme, dan sektarianisme yang sudah berkembang di kalangan masyarakat Islam. Politisasi agama semakin meruncing sejak terbentuknya berbagai kelompok dan ormas keislaman lantaran masingmasing bersikeras ingin menunjukkan eksistensi dan kebenaran gagasan, pandangan, dan gerakan keislaman yang yang diusungnya. Penting untuk dicatat bahwa terbentuknya aneka ormas keislaman ini bukan hanya sekedar untuk "menampung aspirasi" Islam umat saja tetapi juga sebagai strategi untuk merawat faksionalisme dan sektarianisme itu.

Politisasi agama semakin berhembus kencang ketika "Indonesia" merdeka dan hendak merumuskan dasar-dasar politik pemerintahan dan kenegaraan. Masingmasing faksi umat Islam-kelompok tradisionalis, reformis, Islamis, sosialis dan seterusnya-bersikeras menginginkan Indonesia berbasis ideologi politik sesuai dengan spirit gerakan mereka. Puncak dari brutalnya politisasi agama adalah ketika Indonesia memasuki "era partai politik" tahun 1950an. Sejumlah ormas Islam bukan hanya menyokong partai politik tertentu yang sesuai dengan spirit dan gerakan mereka tetapi bahkan ada yang menjelma menjadi parpol seperti NU yang dulu menjadi Partai Nahdlatul Oelama (PNO). 
Tak bisa dipungkiri, terbentuknya aneka partai politik di era 1950an membuat politisasi agama semakin menggila dan ekstrim. Kala itu, politik identitas berbasis agama, etnis, dan ideologi tertentu marak sehingga membuat faksionalisme dan sektarianisme semakin menggila dan membahana. Bung Karno awalnya membiarkan faksi-faksi itu. Tetapi belakangan ia memberangus kelompok atau faksi tertentu (misalnya Masyumi) yang berseberangan dengan "spirit dan cita-cita revolusi".

Pak Harto dan rezim Orde Baru, seperti diuraikan sebelumnya, memang anti terhadap politik identitas berbasis SARA” (Suku, Agama, Ras, dan Antargolongan). Pak Harto juga anti terhadap faksi Islam politik, dan oleh karena itu, ia "membonsai” aneka ragam kelompok Islam politik dalam sebuah "parpol mainan" yang bisa diawasi dan dikontrol, yaitu PPP (Partai Persatuan Indonesia).

Jadi, meskipun Pak Harto dan rezim Orde Baru mengawasi gerak-gerik kelompok Islam politik dan aneka gerakan berbasis SARA, bukan berarti politisasi agama tidak ada. Di zaman Orde Baru, politisasi agama tetap eksis dilakukan oleh sekelompok umat Islam, baik sebagai medium perlawanan terhadap kekuasaan maupun sebagai alat legitimasi kekuasaan. Kedua kelompok atau kubu Islam ini sama-sama memolitisir dan mengeksploitasi" agama Islam. Contoh, ketika Orde Baru dulu mengumumkan program Keluarga Berencana (KB) dan kewajiban umat Islam untuk mengikuti program KB, umat Islam pun terbelah. Tapi baik yang pro maupun yang kontra sama-sama memolitisir agama Islam.

Para tokoh, ulama, dan kiai yang menjadi pendukung Golkar, PDI, maupun PPP sama-sama mengutip ayat, memakai dalil naqli, mendengungkan wacana keagamaan, dan menggunakan simbol-simbol keislaman tertentu yang sesuai dengan kepentingan parpol mereka. Misalnya, dulu para ulama PPP menggunakan simbol ka'bah untuk menarik simpati dan memobilisir umat Islam. Bukan hanya itu saja. Mereka juga mengklaim kalau umat Islam yang tidak memilih PPP diragukan kualitas keimanan dan keislaman mereka. Para ulama NU militan yang berada di PPP adalah yang paling getol menyuarakan protes keras terhadap kekuasaan Orde Baru dan Golkar.

Jadi politisasi agama yang marak belakangan di era reformasi pasca Orde Baru ini bukan sesuatu yang baru dan lahir belakangan ini. Politisasi agama bukanlah sebuah "jabang bayi”. Apa yang dilakukan oleh sejumlah parpol masa kini seperti Partai Kesejahteraan Rakyat (PKS) yang gemar mengeksploitasi agama Islam untuk kepentingan politik sempit bukanlah hal baru karena memang 
sudah eksis di Indonesia, terutama sejak 1950an. Apa yang dilakukan oleh sejumlah kelompok Islamis masa kini, baik yang setengah ekstrim maupun yang radikal-militan seperti FPI (Front Pembela Islam), FUI (Forum Umat Islam), HTI (Hizbut Tahrir Indonesia), dan sejenisnya sejatinya hanya mewarisi apa yang dulu pernah dilakukan oleh ormas-ormas Islam.

\section{Dampak Negatif Overdosis Politik Politisasi Agama}

Gerakan overdosis politisasi agama di era pasca-Orde Baru memang telah memakan sejumlah korban para tokoh politik nasional. Mendiang Gus Dur (KH Abdurrahman Wahid) atau Megawati Soekarnoputri hanyalah contoh kecil dari korban politik ekstrim politisasi agama. Jika Gus Dur pernah diserang dengan dalil "orang cacat" tidak boleh menjadi kepala negara, Megawati pernah dibombardir dengan alasan perempuan haram menjadi pemimpin politikpemerintahan. Begitu pula apa yang menimpa pada diri Ahok (Basuki Tjahaja Purnama), mantan Gubernur Jakarta, yang menjadi korban terheboh tragedi aksi dan gerakan politisasi agama kontemporer dan kini sedang menyasar ke Presiden Joko Widodo hanyalah sekelumit contoh dari politisasi agama yang sudah sekian lama mengakar dalam sejarah sosial Indonesia. Sejumlah politisi lokal juga banyak yang menjadi korban atau terkena dampak politisasi agama seperti Ridwan Kamil, Dedi Mulyadi, Djarot Saiful Hidayat, dlsb.

Bukan hanya memakan korban para politisi dan tokoh (nasional, regional, atau lokal) saja. Politik politisasi agama yang berlebihan (sebagaimana politisasi identitas lain: etnisitas, kesukuan, ideologi, dlsb) telah menyebabkan rontoknya sendi-sendi kemanusiaandan ambruknya spirit persaudaraan universal. Apa yang terjadi di Amerika, Jerman, Afrika Selatan, dan lainnya, dengan politik politisasi etnis atau ras yang berlebihan, masih membekas hingga kini dan nyaris tak bisa dilupakan. Apa yang terjadi di Turki dengan politik politisasi sekularisme Mustafa Kemal juga masih membekas hingga dewasa ini.

Begitu pula di Indonesia. Overdosis politik politisasi agama telah memakan banyak korban. Ambon atau Maluku secara umum adalah contoh dari korban overdosis politik politisasi agama. Masyarakat menjadi semakin tersegregasi ke dalam ghetto-ghetto faksionalisme dan sektarianisme tertentu. Politisasi agama yang berlebihan juga menyebabkan masyarakat menjadi abai akan pentingnya nilai-nilai kemanusiaan dan persaudaraan. Hingga kini, politisasi agama yang brutal dan tak beretika yang terjadi di Jakarta saat tragedi penggulingan Ahok juga berdampak pada rapuhnya relasi antarmasyarakat dan umat Islam itu 
sendiri serta ketidakpercayaan dan pesimisme di kalangan masyarakat atas eksistensi dan masa depan bangsa mereka. Bukan hanya itu saja, overdosis politik politisasi agama itu telah membuat Islam dicibir dimana-mana dan menjadi tampak buruk rupa seolah-olah agama ini menghalalkan berbagai macam cara untuk menggapai kekuasaan.

Banyak sekali individu dan kelompok masyarakat yang menjadi korban politisasi agama yang berlebihan ini. Lihat misalnya hubungan tidak harmonis antara umat Muhammadiyah dan NU.Pengikut kedua ormas ini, baik yang elit maupun massa, baik yang terdidik maupun yang awam, baik yang tinggal di perkotaan maupun pedesaan,susah sekali untuk berdamai. Kalaupun mereka kadang-kadang berdamai, khususnya kalangan elit kedua ormas ini, itupun penuh dengan kepura-puraan. Apakah perseteruan NU-Muhammadiyah itu merupakan "produk kontemporer"? Jelas bukan. Hubungan buruk pengikut kedua ormas ini merupakan "produk klasik" atau "buntut perseteruan" wong NU dan orang Muhammadiyah sejak awal abad ke-20!

Jika dulu ormas Islam masih terbatas, kini ormas Islam menjamur dimanadimana. Para pendatang baru ormas Islam, baik produk lokal maupun impor, dari berbagai aliran, mazhab, dan ideologi, berhamburan dimana-amana. Indonesia kini adalah "surga" bagi para ormas keislaman yang dulu di zaman Orde Baru menjadi "neraka". Semakin banyak ormas Islam, tentu saja tantangannya akan jauh semakin besar. Eksistensi Bangsa Indonesia akan terus diuji oleh beragam kelompok yang hobi melakukan politisasi agama, etnis, daerah, dlsb.

Saya hanya bisa berharap semoga bangsa dan Tanah Air tercinta ini bisa tabah dan tahan banting menghadapi segala daya-upaya politik politisasi identitas primordial apapun. Karena sudah terjadi sejak dulu, saya berharap masyarakat Indonesia semakin dewasa dalm menyikapi dan menghadapi aneka ragam politik identitas ini. Saya juga berharap individu dan kelompok Islam yang selama ini sering melakukan politisasi agama untuk minimal meminimalisir politik politisasi identitas primordial itu dan memulai menggunakan politik profesional-intelektual yang elegan demi terperliharanya Indonesia tercinta.

Ibarat rumah, Indonesia bukan hanya dihuni oleh kaum Muslim saja tetapi juga umat non-Muslim yang sudah semestinya mendapat hak yang sama dengan kaum Muslim karena mereka (umat non-Muslim) memiliki kewajiban yang sama dengan umat Islam sebagai anggota keluarga. Karena itu alangkah eloknya jika masing-masing pihak dan kelompok etnis-agama di Indonesia bersikap toleran 
dan tidak arogan karena negara ini bukan hanya didirikan oleh umat Islam saja tetapi juga oleh umat agama lain.

Politisasi agama boleh-boleh saja asal dilakukan secara wajar dan tidak berlebihan. Agama juga boleh-boleh saja "dipolitisir" untuk kepentingan keadilan sosial dan kemaslahatan publik luas, bukan untuk kepentingan sempit individu dan kelompok tertentu.Politisasi agama juga boleh-boleh saja asal dilakukan demi merawat spirit persaudaraan antarumat, nilai-nilai kemanusiaan, dan cita-cita kebangsaan. Wa Allahu a'lam bi-shawwab.

\section{Daftar Pustaka}

Al Qurtuby, Sumanto. 2013. "The Islamic Roots of Liberation, Justice, and Peace: an Anthropocentric Analysis of the Concept of Tauhid. Islamic Studies 52 (3-4): 297-325.

Engineer, Asghar Ali. 1990. Islam and Liberation Theology: Essays on Liberative Elements on Islam. Stosius Inc / Advent Book Division.

Esack, Farid. 1996. Qur'an, Liberation, and Pluralism: an Islamic Perspective of Interreligious Solidarity against Oppression. London, U.K: Oneworld Publications.

Fox, Jonathan. 2012. An Introduction to Religion and Politics: Theory and Practice. London \& New York: Routledge.

Glock, Charles dan Rodney Stark. 1965. Religion and Tension in Society. Chicago: Rand McNelly \& Co.

Ivanescu, Carolina. 2013. "Politicised Religion and the Religionization of Politics. Culture and Religion: an Interdisciplinary Journal 11 (4): 309-25.

Kalyvas, Stathis. 1996. The Rise of Christian Democracy in Europe. Ithaca, NY: Cornell University Press.

Patrikios, Stratos. 2007. "The Politicization of Religion in the US". Helsinski: ECPR Joint Sessions of Workshops.

Sonn, Tamara. 2015. Islam: History, Religion, and Politics. Hoboken, NJ: WileyBlackwell.

Stein, Rebecca and Phillip L Stein. 2017. The Anthropology of Religion, Magic and Witchcraft. London and New York: Routledge.

Stiles, Daniel. 1993. "Nomads on Notice”. Natural History 9: 51-6. 